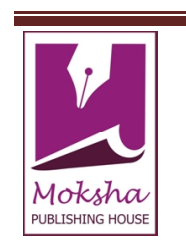

INTERNATIONAL RESEARCH JOURNAL OF PHARMACY

www.irjponline.com

ISSN $2230-8407$

Research Article

\title{
AUGMENTING POTENTIAL ANTIFUNGAL ACTIVITY OF GANDHAKA RASAYANA (A SIDDHA COMPOUND) USING GREEN SYNTHESIZED SILVER NANOPARTICLES FROM COUROUPITA GUIANENSIS LEAF EXTRACT AGAINST SELECTED PATHOGENIC STRAINS
}

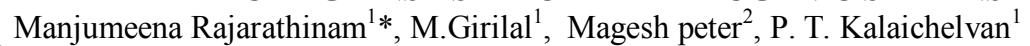

${ }^{1}$ CAS in Botany, University of Madras, Guindy Campus, Chennai 600025, India

${ }^{2}$ National Institute of Ocean Technology, Pallikaranai, Chennai 600036, India

*Corresponding Author Email: manjumeena1989@gmail.com

Article Received on: 19/03/13 Revised on: 01/04/13 Approved for publication: 12/05/13

DOI: $10.7897 / 2230-8407.04653$

IRJP is an official publication of Moksha Publishing House. Website: www.mokshaph.com

(C) All rights reserved.

\section{ABSTRACT}

In the present study, augmented antifungal activity of Gandhaka Rasayana in the presence of biosynthesized silver nanoparticles against selected Candida spp. has been demonstrated. Silver nanoparticles were biologically synthesized from the leaf extract of Couroupita guianensis. The stable silver nanoparticles were characterized by means of UV-Vis spectrophotometer, XRD, TEM, EDX and FTIR; the nanoparticles exhibited maximum absorbance at 415 nm in the UV spectrum. The presence of proteins and functional group was identified by FTIR. TEM micrograph revealed the formation of polydispersed nanoparticles and the presence of elemental silver was confirmed by EDS analysis. The antifungal activity of Gandhaka Rasayana drastically increased in the presence of lower concentration of biologically synthesized silver nanoparticles. This would be helpful in reducing the side effects caused by the excess use of the drug.

Keywords: Augmented antifungal, biosynthesis, Couroupita guianensis, Candida, Gandhaka Rasayana, Silver nanoparticles,

\section{INTRODUCTION}

Nano-materials have been receiving considerable attention because of their distinct physical, chemical and biological properties and their important applications in optics, electronics, biomedicine, magnetics, mechanics, catalysis and energy science ${ }^{1}$. There is a growing need to develop an environment friendly process for the synthesis of nanoparticles that does not employ any toxic chemicals. Generally, nanoparticles are prepared by a variety of chemical and physical methods ${ }^{2-5}$, which are not environment friendly. However nowadays, green chemistry procedures using various biological systems such as yeast, fungi, bacteria and plant extract ${ }^{6-8}$ are commonly used for the synthesis of nanoparticles. Among them, plant extract based biosynthesis of metal nanoparticles especially silver and gold with controlled physicochemical properties have been reported by many researchers ${ }^{9-11}$.

In the present scenario, nanoscale materials have emerged as novel antimicrobial agents owing to their high surface area to volume ratio and unique chemical and physical properties ${ }^{12,13}$ In recent years, a rapid increase in microbes that are resistant to conventional antibiotics has been observed ${ }^{14}$. Especially, the frequency of infections provoked by opportunistic fungal strains has increased drastically. In such scenarios, nanoscale materials have emerged as novel antimicrobial agents ${ }^{15,16}$.

Candida spp, one of the most important human pathogenic yeasts, is directly attacked by the host innate immune system upon infection. However, this pathogen has developed multiple strategies to escape the host's immune defense. Even though the majority of invasive fungal infections are still due to the Candida spp. the spectrum of fungal pathogens has greatly diversified ${ }^{17-19}$. The increases in resistance among different pathogenic strains and the side effects associated with prolonged use of antibiotics have prompted research on new antifungal agents.

Gandhaka Rasayana [a siddha compound] is a proprietary used in treating skin diseases like kandu, visarpa and dadru ${ }^{20}$. Thus based on its use in treating certain skin diseases since ancient times, present study on Gandhaka Rasayana was undertaken to augment the efficacy as an antifungal agent specially in Candida sp. using green synthesized silver nanoparticles from Couroupita guianensis leaf extract.

\section{MATERIALS AND METHODS \\ Chemicals}

Silver nitrate received from Merck (Darmstadt, Germany), potassium dihydrogen phosphate, dipotassium hydrogen phosphate, magnesium sulfate heptahydrate, and ammonium sulphate procured from SRL (Mumbai, India), glucose from Rankem (Mumbai, India) and Muller-Hinton agar from Himedia (Mumbai, India) were used.

\section{Source of Microorganisms}

The strains Candida tropicalis, C. krusei, C.glabrata, C.albicans were obtained from VHS hospital, Chennai, India.

\section{Preparation of leaves extract}

Aqueous extract of Couroupita guianensis (Cannon ball tree) (Figure 1) was prepared using freshly collected leaves $(10 \mathrm{~g})$. The leaves were surface cleaned with running tap water, followed by distilled water and boiled with $100 \mathrm{ml}$ of distilled water at $60{ }^{\circ} \mathrm{C}$ for $10 \mathrm{~min}$. This extract was filtered through nylon mesh, followed by Millipore filter $(0.45$ micron metre). Filtered leaf extract was stored at $-4 \circ \mathrm{C}$ for further use, being usable for 1 week.

\section{Synthesis of silver nanoparticles}

$60 \mathrm{~mL}$ aqueous solution of $1 \mathrm{mM}$ of silver nitrate was reduced using $2.5 \mathrm{~mL}$ of leaves extract at room temperature for $10 \mathrm{~min}$, This setup was incubated in dark (to minimize the photoactivation of silver nitrate), under static condition resulting in a brown-yellow indicating the formation of silver (AgNPs).control setup was also maintained without the leaf extract (Figure 2).

\section{Gandhaka Rasayana bound silver nanoparticles}

Gandhaka Rasayana bound AgNPs were prepared by stirring $10 \mathrm{~mL}$ of biologically synthesized AgNPs with Gandhaka 
Rasayana (5 mg/mL concentration) for 15 minutes and kept overnight at room temperature. After $24 \mathrm{hr}$ of incubation the solution was centrifuged and the pellet was collected for resuspension in sterile glass distilled water and stored in refrigerator for further studies.

\section{Characterization of the synthesized nanoparticles}

Surface plasmon resonance of silver nanoparticles after the synthesis by reducing metal ion solution with leaves extract can be easily confirmed by UV-vis spectroscopy. The reaction mixture was sampled at regular intervals and the absorption maxima was scanned at the wavelength of 400 $800 \mathrm{~nm}$ in UNICAM UV 300 spectrophotometer. The biologically synthesized AgNps gave sharp peak in the visible region of the electromagnetic spectrum. The X-ray powder diffraction data was acquired by PANalytical X'Pert PRO diffractometer in Bragg-Brentano geometry using stepscan technique and Johansson monochromator to produce pure $\mathrm{Cu} \mathrm{K} 1$ radiation $(1.5406 \AA ; 45 \mathrm{kV}, 30 \mathrm{~mA})$ in the range of $20^{\circ}-90^{\circ}$. The peaks matched with JCPDF Card No087-0720. The obtained pattern is for fcc cubic crystal structure. The peak plane matches with the card. The crystalline size is calculated from the full-width at halfmaximum (FWHM) of the diffraction peaks using the Debye-Sherrer formula

$$
\mathrm{D}=0.89 \lambda / \beta \cos \theta
$$

where $\mathrm{D}$ is the mean grain size, $\lambda$ is the $\mathrm{X}$-ray wavelength for $\mathrm{Cu}$ target, $\beta$ is the FWHM of diffraction peak and $\theta$ is the diffraction angle.

In order to measure the size of nanoparticles accurately each peak is Gaussian fitted and also the instrumental broadening is subtracted using $\mathrm{Si}$ standard sample broadening. For transmission electron microscope (TEM) measurements, a drop of solution containing as- synthesized silver nanoparticles was placed on the carbon coated grids and kept under vacuum desiccation for overnight before loading them onto a specimen holder. TEM micrographs were taken by analyzing the prepared grids on $300 \mathrm{kv}$ field emission TEM-
STEM (FEI F30) with capability of HAADF, FELS and EDX. The FT-IR spectra for biologically synthesized AgNPs, Gandhaka Rasayana, and their combination were recorded on a IR Affinity-1 SHIMADZU spectrophotometer in transmittance mode in the range of $400-4000 \mathrm{~cm}^{-1}$ at a resolution of $4 \mathrm{~cm}^{-1}$.

\section{Augmenting potential antifungal activity of Gandhaka Rasayana using biologically synthesized silver nanoparticles}

The antifungal activity of biologically synthesized AgNPs, Gandhaka Rasayana, and Gandhaka Rasayana bound AgNPs was investigated by the micro-dilution method ${ }^{21}$. The cultures were inoculated from fresh colonies on agar plates into $100 \mathrm{~mL}$ Muller Hinton culture medium. The cultures were allowed to grow until the optical density reached 0.2 at $600 \mathrm{~nm}$ (OD of 0.2 corresponding to a concentration of $10^{8}$ $\mathrm{CFUmL}^{-1}$ of medium). Various dilutions of biologically synthesized AgNPs, Gandhaka Rasayana, and Gandhaka Rasayana bound AgNPs were added to the fungal culture (individually) in the 96 well micro-titer plate in a sequence and immediately after inoculation, the micro-titer plate was covered with a clear tape to prevent the culture medium from drying out. The inoculated micro-titer plates were incubated at room temperature for 48 hours in the shaker to maintain uniformity in the growth of the microbes. After the incubation the absorbance of the sample was measured at the wavelength of $600 \mathrm{~nm}$ in the ELISA plate reader Biotek, power wave XS.

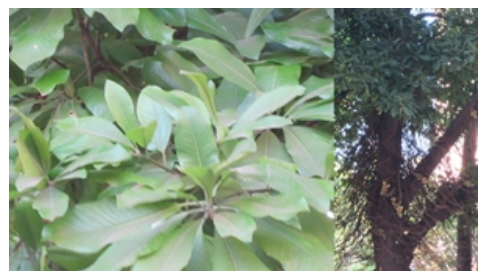

Figure 1: Couroupita guianensis leaves and the tree in a natural habitat

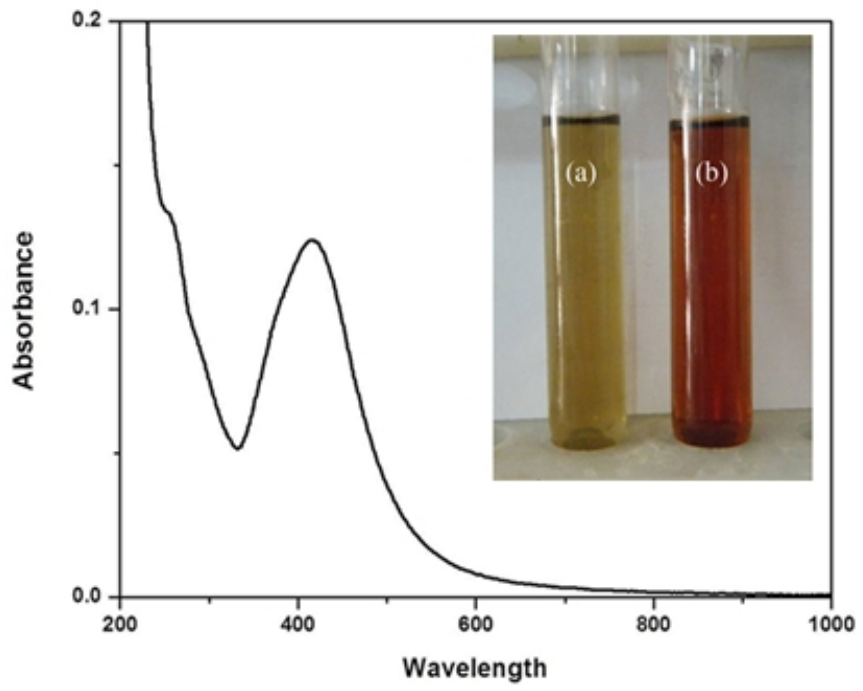

Figure 2: UV-Vis spectrum of the biologically synthesized silver nanoparticles after the reaction with aqueous silver nitrate and leaf extract. Inset: Test tubes with (a) Couroupita guianensis leaf extract (b) synthesized silver nanoparticles 


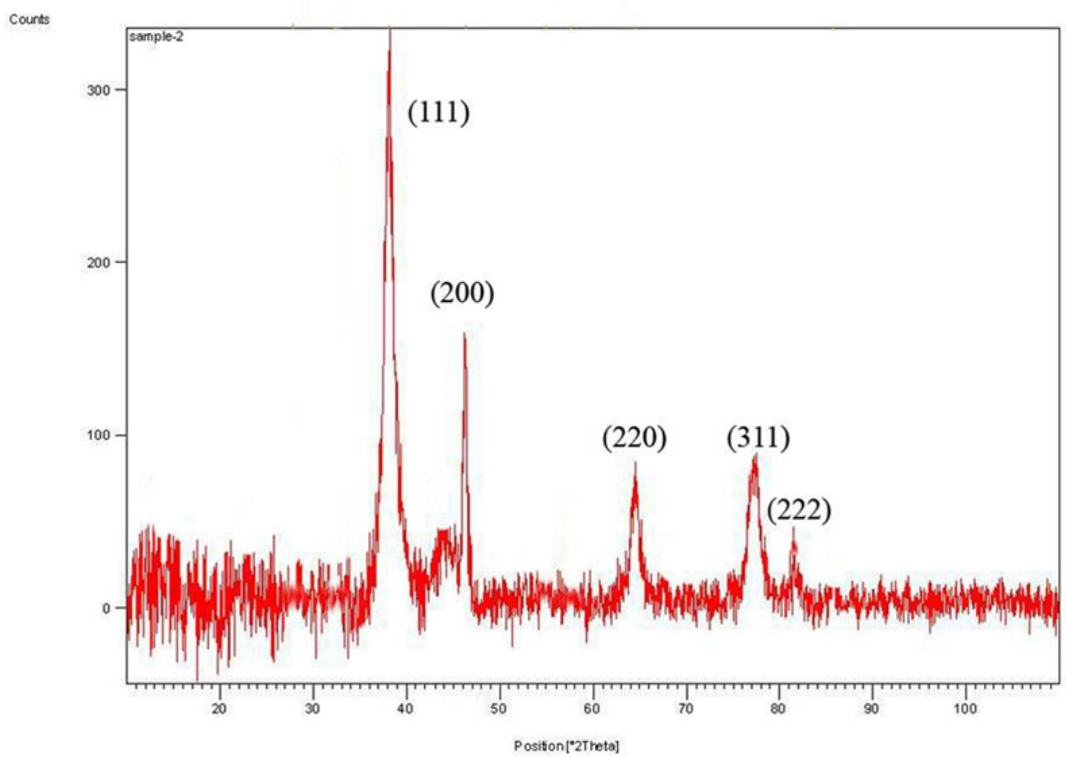

Figure 3: XRD pattern of silver nanoparticles with lattice planes
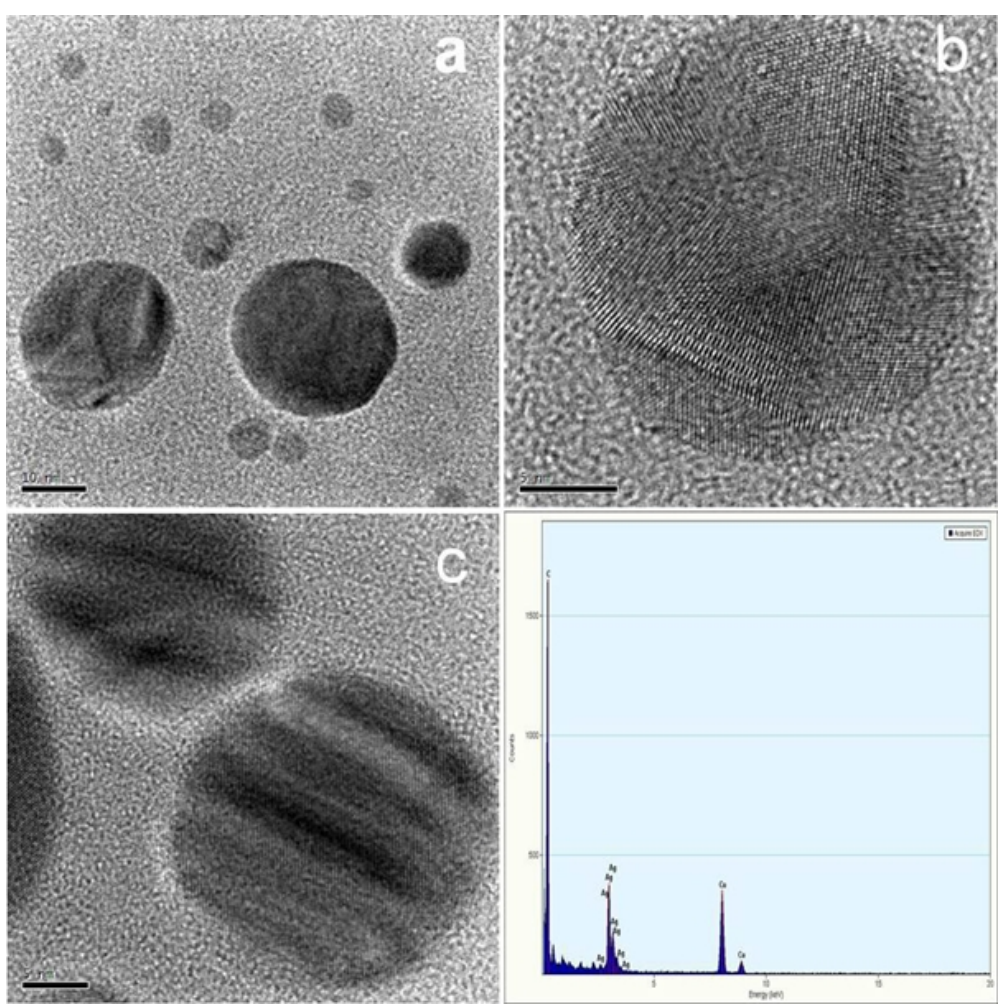

Figure 4: HrTEM micrograph of biologically synthesized Silver nanoparticles showing various size and lattice fringes and EDS spectrum of silver nanoparticles 


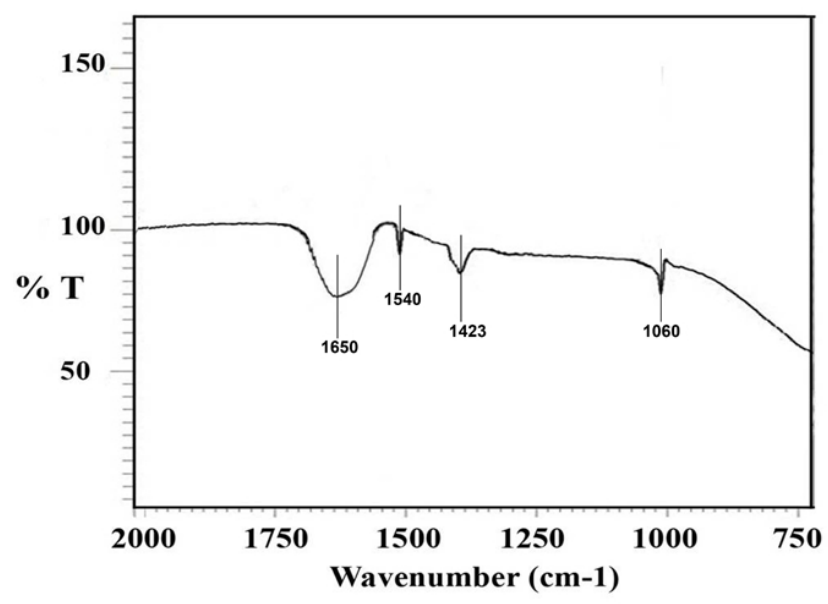

Figure 5: FTIR spectrum of the biosynthesized AgNPs

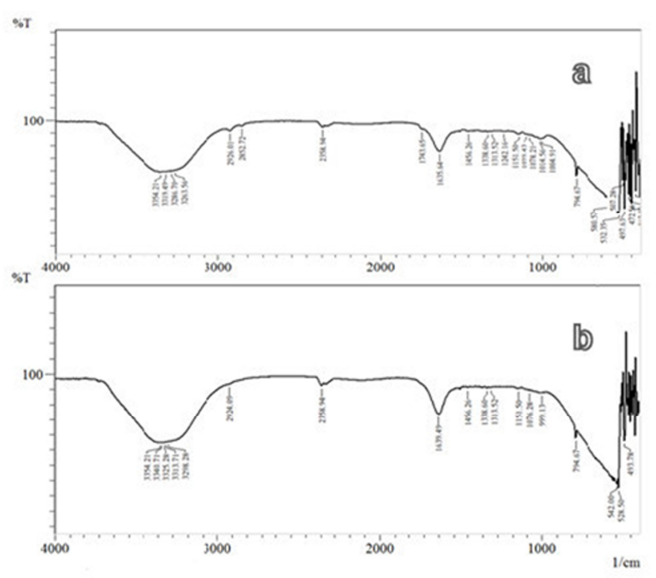

Figure 6: a. FTIR spectrum of Gandhaka Rasayana, b. FTIR spectrum of Gandhaka Rasayana bound AgNPs
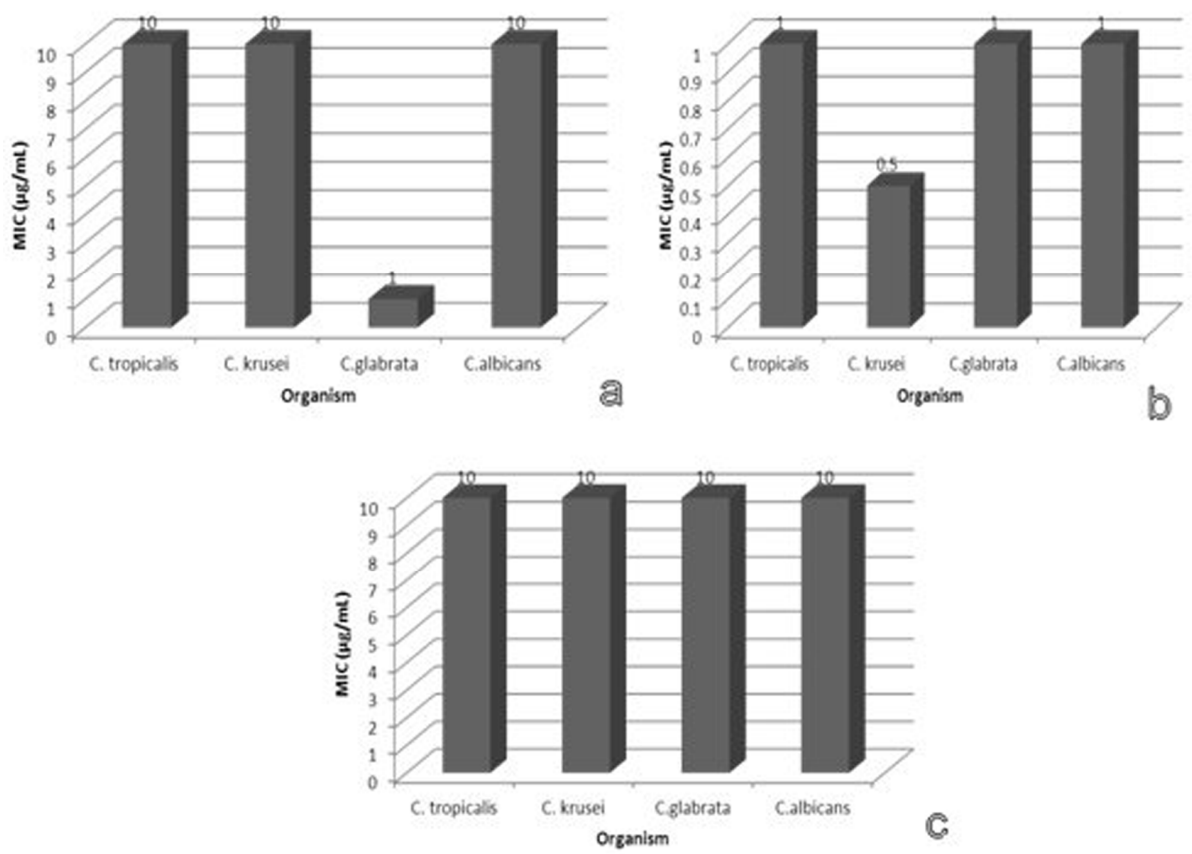

Figure 7: a. MIC of biosynthesized AgNPs against selected fungal strains. b. MIC of Gandhaka Rasayana bound AgNPs against selected fungal strains. c. MIC of Gandhaka Rasayana against selected fungal strains 
RESULTS AND DISCUSSION

UV-vis spectra analysis

UV-vis spectroscopy is an important technique to ascertain the formation and stability of metal nanoparticles in aqueous solution. Figure 2. shows a characteristic surface plasmon resonance band for synthesized AgNPs, centred at $415 \mathrm{~nm}$. Intensity of brown color increased in direct proportion to the incubation period. It may be due to the excitation of surface plasmon resonance (SPR) effect and reduction of $\mathrm{AgNO}_{3}{ }^{22}$. Metal nanoparticles such as silver have free electrons, which give rise to surface plasmon resonance (SPR) absorption band $^{23}$. This result implies that the AgNPs prepared by green synthesis method is very stable without aggregation. The stability results from a potential barrier that develops as a result of the competition between weak Vander Waals forces of attraction and electrostatic repulsion ${ }^{24}$.

\section{Powder X-ray diffraction}

The crystalline nature of AgNPs was confirmed from X-ray diffraction (XRD) analysis. Figure 3 shows the XRD pattern of the synthesized AgNPs. The five diffraction peaks were observed at $38.2^{\circ}, 44.4^{\circ}, 64.6^{\circ}, 77.6^{\circ}, 81.7^{\circ}$ in the $2 \theta$ range can be indexed to the (111) (200) (220) (331) and (222) reflection planes of face centred cubic structure of metallic silver nano powders. The mean size of the biosynthesized silver nanoparticles was determined to be in the range of $5-15 \mathrm{~nm}$. The calculated lattice parameter was found to be $4.08 \AA$.

\section{HR-TEM and EDX analysis}

The HrTEM technique was used to visualize the size and shape of the synthesized silver nanoparticles. Figures $4 \mathrm{a}, 4 \mathrm{~b}$ and $4 \mathrm{c}$ show the typical bright field HrTEM micrograph of the synthesized silver nanoparticles. The observed morphology of nanoparticles in the micrograph is spherical . The HrTEM micrograph suggests that the size of the particles is around $5-15 \mathrm{~nm}$. In EDX analysis, Figure 4 shows the peak in silver region which confirms the presence of elemental silver, indicating the reduction of silver ions to elemental silver. The peak was observed approximately at $3 \mathrm{KeV}$, typical for the absorption of metallic silver nanocrystallites ${ }^{25}$.

\section{FT-IR analysis}

FTIR measurements were used to identify the possible biomolecules responsible for reduction, stabilization of the AgNPs and the binding of AgNPs to Gandhaka Rasayana. The AgNPs were stabilized in the solution by capping agents which are likely to be proteins present in the leaves extract. Figure 5 shows the FTIR spectrum of the synthesized AgNPs. The spectrum shows the presence of bands at 1650 , 1540,1423 and $1060 \mathrm{~cm}^{-1}$. The band at 1650 correspond to primary amine $\mathrm{NH}$ band, and those at 1540 and 1060 correspond to secondary amine $\mathrm{NH}$ band and primary amine $\mathrm{CN}$ stretch vibrations of the proteins, respectively ${ }^{26}$. The positions of these bands were close to those reported for native proteins ${ }^{27}$. The FTIR result indicates that the secondary structures of proteins were not affected by the reaction with $\mathrm{Ag}^{+}$ions or binding with $\mathrm{AgNPs}^{28}$. Figure 6 shows the FTIR spectrum of Gandhaka Rasayana, and Gandhaka Rasayana bound AgNPs. The spectrum of Gandhaka Rasayana bound AgNPs shows the presence of new bands at $3340 \mathrm{~cm}^{-1}$ and $3313 \mathrm{~cm}^{-1}$ which corresponds to aromatic primary amine N-H stretch and aliphatic secondary amine $\mathrm{NH}$ stretch respectively.
Augmenting potential antifungal activity of Gandhaka Rasayana using biologically synthesized silver nanoparticles

The minimum inhibitory concentrations (MIC) of the synthesized AgNPs, Gandhaka Rasayana, and Gandhaka Rasayana bound AgNPs against fungal strains were determined and compared as shown in Fig.7. The results showed that the MIC for fungal strains decreased considerably after binding the biosynthesized AgNPs with Gandhaka Rasayana when compared with the MIC of AgNPs and Gandhaka Rasayana separately. The ability of silver nanoparticles to destroy fungal cell electric potential and membrane function also has been already well documented. Silver nanoparticles breaks down the membrane permeability barrier by acting on ergosterol in the fungal lipid bilayer causing the leakage of ions and other materials forming pores and dissipating the electrical potential of the membrane which finally leads to cell death ${ }^{29}$. Several studies suggest that AgNPs may attach to the surface of the cell membrane disturbing permeability and respiration functions of the cell ${ }^{30}$. It has been suggested that for metallic Ag there is interaction of silver species with the sulphydryl groups of respiratory enzymes in the plasma membranes of susceptible microorganisms $^{31}$. This causes changes in the membrane permeability, known to have consequences in the cell, including detachment of the plasma membrane from the cell wall. The binding of $\mathrm{Ag}^{+}$to microbial genetic material is another hypothesis that has been reported in the work done by J.Keleher and co-workers ${ }^{32}$. Antifungal activity is due to the formation of insoluble compounds by inactivation of sulfhydryl groups in the fungal cell wall and disruption of membrane bound enzymes and lipids which causes cell lysis $^{33}$.

The dimorphic transition of $C$. albicans from yeast form to mycelial form is responsible for pathogenicity, with mycelial shapes predominantly found during the invasion of host tissue. A mycelial form can be induced by temperature, $\mathrm{pH}$, and serum. This could be one of the reasons for the difference in MIC of the biologically synthesized AgNPs against C.albicans when compared to the other selected fungal strains $^{34}$.

Despax et al proposed that granules were formed inside the fungal cell along with serious structural and morphological damage on cellular membranes when fungi were treated with AgNPs. Granules composed of Ag, sulfur, phosphorous, and nitrogen on cellular walls and in the cytoplasm of yeast, with higher concentrations on cellular walls ${ }^{35}$. In addition ionic silver released from silver nanoparticles can inhibit the respiratory enzymes and can induce oxidative stress upon generation of reactive oxygen species $(\mathrm{ROS})^{36}$.

\section{CONCLUSION}

Silver nanoparticles thus synthesized by simple, low cost, non-toxic and eco- friendly green route using the leaf extract of Couroupita guianensis proved to be an effective alternative for the development of new antifungal agents. The microorganisms are unlikely to develop resistance against silver as compared to antibiotics as silver attacks a broad range of targets in the microbes. The silver nanoparticles with their unique chemical and physical properties reduced the pathogenicity of Candida spp by their synergistic effect with Gandhaka Rasayana. There was a drastic increase in the antifungal activity even in lower concentrations. 


\section{ACKNOWLEDGEMENT}

We would like to thank Dr.R. Kirubagaran, Scientist F, Group head, Marine Biotechnology, National Institute of Ocean Technology, Chennai and Dr. K. Gopalakrishnan Member, Board of Governors, National Design and Research Forum, Bangalore for providing instrumentation facility. We would also like to thank Prof. R. Rengasamy, Director, CAS in Botany, University of Madras, Guindy campus for providing lab facilities.

\section{REFERENCES}

1. Klaus JT, Joerger EO, Granqvist CG. Bacteria as workers in the living factory: metal- accumulating bacteria and their potential for materials science. Trends Biotechnol. 2001; 19: 15-20 http://dx.doi.org/10.1016 /S0167-7799(00)01514-6

2. Yu DG. Formation of colloidal silver nanoparticles stabilized by $\mathrm{Na}+-$ poly $(\gamma$-glutamic acid)-silver nitrate complex via chemical reduction process. Colloids Surf. B. 2007;59: 171-178. http://dx.doi.org/10.1016 j.colsurfb.2007.05.007 PMid:17583483

3. Mallick K, Witcombb MJ, Scurrella MS. Self-assembly of silver nanoparticles in a polymer solvent: Formation of a nanochain through nanoscale soldering. Mater. Chem. Phys. 2005; 90: 221-224. http:// dx.doi.org/10.1016/j.matchemphys.2004.10.030

4. Liu YC, Lin LH. New pathway for the synthesis of ultrafine silver nanoparticles from bulk silver substrates in aqueous solutions by sonoelectrochemical methods. Electrochem. Commun. 2004; 6: 1163 1168. http://dx.doi.org/10.1016/j.elecom.2004.09.010

5. Smetuna AB, Klabunde KJ, Sorensea CM. synthesis of spherical silver nanoparticles by digestive ripening stabilization with various agents, and their 3-D and 2-D superlattice formation. J. Colloid Interface Sci. 2005; 284:521-526.http://dx.doi.org/10.1016/j.jcis.2004.10.038PMid:157802 91

6. Kowshik M, Ashtaputre S. Kharrazi S. Vogel W, Urban J, Kulkarni SK, Paknikar KM, Extracellular synthesis of silver nanoparticles by a silvertolerant yeast strain MKY3. Nanotechnology. 2003; 14: 95-100. http:// dx.doi.org/10.1088/0957-4484/14/1/321

7. Senapati S, Ahmad A, Khan MI, Sastry M, Kumar R. Extracellular Biosynthesis of Bimetallic Au-Ag Alloy Nanoparticles. Small. 2005; 1: 517-520. http://dx.doi.org/10.1002/smll.200400053 PMid:17193479

8. Shahverdi AR, Minaeian S, Shahverdi HR, Jamalifar H, Nohi AA. Rapid synthesis of silver nanoparticles using culture supernatants of Enterobacteria: A novel biological approach. Process Biochem. 2007; 42 919-923. http://dx.doi.org/10.1016/j.procbio.2007.02.005

9. Badri Narayanan K, Sakthivel N. Coriander leaf mediated biosynthesis of gold nanoparticles. Mater. Lett. 2008; 62: 4588-4590. http:/ /dx.doi.org/10.1016/j.matlet.2008.08.044

10. Prathap Chandran S, Chaudhary M, Pasricha R, Ahmad A, Sastry M. Synthesis of gold nanotriangles and silver nanoparticles using Aloe vera plant extract Biotechnol. Prog. 2006; 22: 577-583. http://dx.doi.org /10.1021/bp0501423 PMid: 16599579

11. Dubey SP, Lahtinen M, Sarkka H, Sillanpaa M. Green synthesis and characterizations of silver and gold nanoparticles using leaf extract of Rosa rugosa. Colloids Surf. B: Biointerfaces. 2010; 80: 26-33. http:/ /dx.doi.org/10.1016/j.colsurfb.2010.05.024 PMid:20620889

12. Sharma VK, Yngard RA, Lin Y. Silver nanoparticles: Green synthesis and their antimicrobial activities. Advances in Colloid and Interface Science. 2009; 145: 83- 96 http://dx.doi.org/10.1016/j.cis.2008.09.002 PMid: 18945421

13. Kim JS, Kuk E, Yu KN, Kim JH, Park SJ, Lee HJ. Antimicrobial effects of silver nanoparticles. Nanomed Nanotechnol Biol Med. 2007; 3: 95101. http://dx.doi.org/10.1016/j.nano.2006.12.001 PMid:17379174

14. Goffeau A. Drug resistance: the fight against fungi. Nature. 2008; 452 541-542. http://dx.doi.org/10.1038/452541a PMid:18385723

15. Morones JR, Elechiguerra JL, Camacho A, Ramirez JT. The bactericidal effect of silver nanoparticles. Nanotechnology. 2005;16: 2346-2353. http://dx.doi.org/10.1088/0957-4484/16/10/059 PMid:20818017

16. Rai M, Yadav A, Gade A. Silver nanoparticles as a new generation of antimicrobials. Biotechnology Advances. 2009; 27: 76-83 http:/ /dx.doi.org/10.1016/j.biotechadv.2008.09.002 PMid:18854209

17. Denning DW. Epidemiology and pathogenesis of systemic fungal infections in the immunocompromised host. J.Antimicrobial Chemother. 1991; 28: 1-16. http://dx.doi.org/10.1093/jac/28.suppl_B.1 PMid: 1778886

18. Ellis M, Richardson M, De-Pauw B. Epidemiology. Hospital medicine, 2000; 61: 605-609. PMid:11048599
19. Odds FC, Brown AJ, Gow NA. Antifungal agents: Mechanisms of action. Trends in microbiology. 2003;11: 272-279. http://dx.doi.org 10.1016/S0966-842X(03)00117-3

20. Sharangdhara, Samhita S. trans Acharya Panashara Radhakrisna, Fourth Edition 1994; Shri Bhaidyanath Ayurved Bhavan Ltd. Allahabad PP-612

21. Shrivastava S, Tanmay BE, Roy A, Singh G. Characterization of enhanced antibacterial effects of novel silver nanoparticles. Nanotechnolgy. 2007; 18: 225103. http://dx.doi.org/10.1088/0957$4484 / 18 / 22 / 225103$

22. Mulvaney P. Surface plasmon spectroscopy of nanosized metal particles Langmuir 1996; 12: 788-800. http://dx.doi.org/10.1021/la9502711

23. Noginov MA, Zhu G, Bahoura M, Adegoke J, Small C, Ritzo BA, Drachev VP, Shalaev VM. The effect of gain and absorption on surface plasmons in metal nanoparticles. Appl. Phys. B. 2007; 86: 455-460. http://dx.doi.org/10.1007/s00340-006-2401-0

24. Prathna TC, Chandrasekaran N, Raichur MA, Mukherjee A. Biomimetic synthesis of silver nanoparticles by Citrus limon (lemon) aqueous extract and theoretical prediction of particle size. Colloids Surf. B. 2011; 82:152-159.http://dx.doi.org/10.1016/j.colsurfb.2010.08.036PMid: 2083 3002

25. Mitrikas G, Deligiannakis Y, Trapalis CC, Boukos N, Kordas G. CW and Pulsed EPR Study of Silver Nanoparticles in a SiO2 Matrix. J. SolGel Sci.Technol. 1998; 13: 503-508.mhttp://dx.doi.org/10.1023 A: 1008654102264

26. Gole A, Dash C, Ramakrishnan V, Sainkar SR, Mandale AB, Rao M. Pepsin-Gold Colloid Conjugates: Preparation, Characterization, and Enzymatic Activity. Langmuir. 2001; 17: 1674-1679. http://dx.doi.org/ $10.1021 / \mathrm{la} 001164 \mathrm{w}$

27. Mac Donald IDG, Smith WE. Orientation of cytochrome $\mathrm{c}$ adsorbed on a citrate -reduced silver colloid surface. Langmuir. 1996; 12: 706-713. http://dx.doi.org/10.1021/la950256w

28. Fayaz AM, Tiwary CS, Kalaichelvan PT, Venkatesan R. Blue orange light emission from biogenic synthesized silver nanoparticles using Trichoderma viride. Colloids and Surf. B: Biointerfaces. 2010; 75: 175178. http://dx.doi.org/10.1016/j.colsurfb.2009.08.028 PMid:19783414

29. Kim K, Woo SS, Bo KS, Seok-Ki M, Jong-Soo C, Jong GK, Dong GL. Antifungal activity and mode of action of silver nanoparticles on Candida albicans. Biometals, 2009; 22: 235-242. http://dx.doi.org/ 10.1007/s10534-008-9159-2 PMid:18769871

30. Kvitek L, Panacek A, Soukupova J, Kolar MM, Vecerova R, Prucek R. Effect of surfactants and polymers on stability and antibacterial activity of silver nanoparticles (NPs). J. Phys Chem. C. 2008; 112: 5825-5834. http://dx.doi.org/10.1021/jp711616v

31. Semeykina AL, Skulachev VP. Submicromolar Ag+ increases passive $\mathrm{Na}+$ permeability and inhibits the respiration-supported formation of $\mathrm{Na}+$ gradient in Bacillus FTU vesicles. FEBS Lett. 1990; 269: 69-72. http://dx.doi.org/10.1016/0014-5793(90)81120-D

32. Keleher J, Bashant J, Heldt N, Johnson L, Li Y. Photo-catalytic preparation of silver-coated $\mathrm{TiO} 2$ particles for antibacterial applications. World J. Microbiol. Biotechnol. 2002; 18: 33-139. http://dx.doi.org/ 10.1023/A: 1014455310342

33. Dorau B, Arango R, Green F. Proceedings of the 2nd Wood-Frame Housing Durability and Disaster Issues Conference, Forest Products Society, Las Vegas, NV. 2004; October 4-6: 133-145.

34. McLain N, Ascanio R, Baker C, Strohaver RA, Dolan JW. Undecylenic acid inhibits morphogenesis of Candida albicans. Antimicrobial agents and Chemotherapy. 2000; 44: 2873-2875. http://dx.doi.org/10.1128/ AAC.44.10.2873-2875.2000 PMid:10991877 PMCid:PMC90168

35. Despax B C, Saulou P, Raynaud L, Datas M, Mercier-Bonin M. Transmission electron microscopy for elucidating the impact of silver based treatments ionic silver versus nanosilver-containing coating on the model yeast Saccharomyces cerevisiae. Nanotechnology. 2011; 22: 175101.http://dx.doi.org/10.1088/0957-4484/22/17/175101 PMid:21411 917

36. Kim JS, Kuk E,. Yu KN, Kim JH, Park SJ, Lee HJ. Antimicrobial effects of silver nanoparticles. Nanomedicine. 2007; 3: 95-101. http://dx.doi.org/10.1016/j.nano.2006.12.001 PMid:17379174

\section{Cite this article as:}

Manjumeena Rajarathinam, M.Girilal, Magesh peter, P. T. Kalaichelvan. Augmenting potential antifungal activity of Gandhaka rasayana (A Siddha compound) using green synthesized silver nanoparticles from Couroupita guianensis leaf extract against selected pathogenic strains. Int. Res. J. Pharm. 2013; 4(6):234-239 